Sobre o Trabalho Teórico

\title{
João Cruz Costa
}

juntamente com Lívio Teixeira, o professor Cruz Costa foi o principal responsável pela criação do Departamento de Filosofia da FFCL da Universidade de São Paulo. A presença entre nós de figuras tais como GillesGaston Granger, Claude Lefort, Martial Guéroult, Michel Debrun, Gérard

Lébrun, Jules Vuillemin, se deveu ao trabalho pioneiro desses dois professores. Cruz Costa tornou-se catedrático em Filosofia pela FFCL/USP no ano de 1951, deixando suas atividades docentes em 1965. Doutor honoris causa pela Universidade de Rennes (França), foi professor convidado da

École de Hautes Études de Paris durante o ano de 1964. Autor de alguns ensaios: A Filosofia no Brasil, $O$ pensamento brasileiro, $O$ desenvolvimento da filosofia no Brasil no século XX e a evolução histórica nacional, Augusto Comte

e as origens do positivismo e Contribuição à história das idéias no Brasil.

Embora modestamente não se defina como um filósofo, mas como "um

filosofante, preocupado com a História", nós o temos como uma das inteligências mais lúcidas e críticas da formação cultural brasileira. Pensador e cultivador das ironias, ao nos enviar carta autorizando a publicação de sua entrevista, assim nos ensinou: "(...) quando tiverem 72 anos como eu, não confiem em microfones. Entrevista, só ali, no duro, na caneta-tinteiro".

Quais foram os principais momentos de seu trabalho teórico? Houve um projeto que o orientou?

Meu projeto teórico? Não sei, não: creio que nunca o tive! Vocês sabem que comecei estudando Medicina, revelando assim um interesse prático pelo homem, se não por ele, por sua saúde... Eu fizera aqui uns vagos estudos de filosofia com o meu saudoso amigo, Prof. Henrique Geenen, para satisfazer as exigências dos preparatórios. Para ingressar na Faculdade de Medicina éramos obrigados a prestar exame de psicologia e lógica, que o meu amigo e professor da Faculdade de Medicina, o Prof. Guilherme Bastos Milward chamava de psicologia ilógica.

Fui depois para a França em 1923 e entrei no curso preparatório à Faculdade de Medicina de Paris. Um dia, num grupo de brasileiros, encontrei o Prof. Georges Dumas, que era grande amigo do Brasil, que me perguntou qual a especialização que en iria fazer na Medicina. A minha resposta foi: a psiquiatria. $\mathrm{O}$ velho Dumas, que era médico e agrégé de 
filosofia, aconselhou-me então que fizesse estudos de filosofia e convidou-me para assistir às suas divertidas (?) aulas aos domingos, no Asyle de St'Anne. Inscrevi-me como ouvinte nos cursos da Sorbonne, assistindo às aulas dos Profs.

Brunschvicg, Lalande, assim como as de Pierre Janet no Colégio de França. Como percebem, não houve, pois, nada de especulativo nos meus desígnios. Ao contrário: as minhas intenções eram práticas.

Vocês me perguntaram também pelos momentos de meu trabalho. Bem, nesse momento (eu tinha de 18 para 19 anos) tive um encontro com dois autores que muito me impressionaram e, ambos, muito preocupados com o destino (digamos assim) do homem: Freud e Marx.

\section{Que projeto orientou a criação da Universidade de São Paulo?}

Parece que esse era um velho sonho, muitas vezes frustrado. Houve um projeto na Colônia; outro no Império e, na República, parece, sério só esse de 1934, no governo de Armando de Salles Oliveira, promovido por Júlio de Mesquita Filho, Fernando de Azevedo e outros de cujos nomes não me lembro agora e que é fácil verificar nos documentos históricos da Universidade.

Qual o projeto? Lévy-Strauss, nos Tristes Tropiques diz que a principal peça criada quando da fundação da Universidade em 1934, - a Faculdade de Filosofia, Ciências e Letras deveria servir de cobertura ideológica ao status quo político e social da época. Em parte talvez tenha sido essa a intenção dos que sonharam com a Universidade, homens cultos, todos eles pertencentes às classes privilegiadas. Mas sejamos justos com essa elite: não foi apenas isto que os moveu. O Brasil já necessitava de arejar e melhorar várias áreas de suas elites, de ampliá-las, dividindo o trabalho intelectual.

\section{Como se constituiu o curso de Filosofia?}

$O$ curso de filosofia foi entregue a um professor francês! $\mathrm{O}$ que iniciou o curso foi o Prof. Etienne Borne, ex-aluno da École Normale Supérieure de Paris, que aqui esteve no primeiro ano letivo. Em 1935 veio nova missão francesa e dela fazia parte o meu amigo Jean Maugüé, também da E.N.S. de Paris e figura brilhante de professor. Teve profunda influência nos jovens que entrariam na Faculdade. Basta relembrar o que dele diz Antônio Cândido na entrevista que lhes deu para o n. ${ }^{0} 1$ de Trans/form/ação.

O Prof. Maugüé nos dava aulas de Psicologia, de Lógica, de História da Filosofia - fêz um notável curso sobre Spinosa - e de Ética.

Depois da partida do Prof. Mauguié, o curso de Filosofia foi dividido entre os seus dois assistentes: Lívio Teixeira com a História da Filosofia e eu, com a Filosofia (Psicologia, Lógica e Ética) . Mais tarde D. Gilda de Mello e Souza ficou encarregada das aulas de Estética. Foi então criado o Departamento de Filosofia.

Desde muito cedo a minha principal preocupação foi a de chamar a atenção dos moços para a aplicação da reflexão à realidade brasileira, como assinalou Antônio Cândido na entrevista já referida. Era, como ele diz, a minha mania. Não me foi difícil o caminho, pois a Semana de Arte Moderna já o preparara em grande parte. Desse modo, o meu trabalho nada teve de especulativo. Nunca fui um filósofo, mas apenas um filosofante, preocupado com a História. O que escrevi fica a cavaleiro entre a Filosofia e a História. 


\section{Qual era o projeto do Departamento?}

A nossa preocupação em desenvolver o Departamento de Filosofia consistiu em apelar para a colaboração de professores estrangeiros, cuja formação era mais completa que a nossa. Vieram vários professores, entre os quais GillesGaston Granger, especialista em Lógica e hoje uma das autoridades no assunto; Martial Guéroult, eminente historiador da Filosofia; Claude Lefort, especialista em ciência política; Michel Debrun, para a disciplina de Ética (e que continua a estudar problemas brasileiros); Gérard Lebrun, para a Filosofia Geral, que ainda há pouco continuava no Departamento. Vieram também Jules Vuillemin, do Colégio de França, para a Lógica e outros mestres que, de passagem, proferiram conferências na Faculdade, como o simpático e vivo Etienne Gilson.

Com estes professores colaboradores, o nosso Departamento foi se diferenciando e produzindo novos especialistas nos diversos ramos da Filosofia. Começou, assim, a tomar uma feição mais especulativa. Entre os novos elementos do Departamento destacaram-se José Arthur Giannotti, Bento Prado, Oswaldo Porchat, João Paulo Monteiro, Maria Helena Chaui que foram os que eu conheci até deixar, em 1965, a Faculdade.

\section{De que maneira a formação cultural brasileira marcou o seu trabalho? Como se situava na cultura brasileira das décadas de 20 e 30 ?}

Em 1920 eu ainda não me situava. Sofria a influência do que lia. Creio que a maioria dos da minha geração estava no mesmo caso. Li todo o Eça de Queiroz, todo o Anatole France, muita coisa de Balzac, de Camilo, de Fialho, de Machado de Assis. Foi a viagem à Europa que me abriu os olhos para outras realidades... 1930, seja lá como for, foi uma encruzilhadä para a cultura brasileira e eu me encontrava, com muitos outros de minha geração, nessa encruzilhada. Uns seguiram pela direita, outros pela esquerda. Mas tudo isso de modo confuso para uns e outros... O espírito crítico que o estudo da Filosofia propicia, ou melhora, ainda não era então dos mais acurados naqueles jovens... Daí as confusões, as falácias, os desenganos, as desilusões. Não creio que a Filosofia, como disciplina acadêmica, ensine muito. Todavia, como escrevia o dominicano Maydieu, embora a "aquisição do filósofo pareça pobre, ela, no entanto, permite coordenar muitas riquezas".

Eu achei que valia a pena dar atenção à riqueza da nossa realidade. Daí o meu trabalho desde então.

Considero, porém, a minha posição uma posição envelhecida, superada. Hoje há uma visão mais universal dos problemas humanos. Felizmente, Mário de Andrade dizia, em carta a Manuel Bandeira, que nós nos abrasileiramos na medida em que nos universalizamos. $\mathrm{Se}$ a filosofia especulativa e a prática nos conduzirem a isso, elas prestarão os serviços que podemos esperar delas.

\section{O que houve de mais característico na cultura paulistana dos anos 30 ?}

Não sei bem, talvez ainda a retórica, o filoneísmo e o elitismo do fim do século passado. Mas houve a Semana de Arte Moderna que foi o escândalo da década dos 20. Em 1930 já havia muita coisa nova.

Como viu as mudanças nesta tradição cultural dos anos 40 e 50 ?

Já então as transformações que se processaram desde a $1 .^{\mathrm{a}}$ Guerra e que 
se acentuariam com a segunda, se faziam sentir no Brasil. Mas apenas numa faixa muito estreita. De 1937 é o Estado Novo. Em 1945 ele termina; o Brasil, porém, não sentiu bem as repercussões desses dois movimentos. Às vezes eu penso que a partir de 45 - sobretudo depois de 1954 - o Brasil retornou, de certo modo, ao que fora antes de 1930. Culturalmente, é verdade, se encontrava, já então, mais bem apetrechado. Mas que faixas de povo atinge a cultura em nossa terra? É o que pergunto. O povo, parece-me, ainda não entrou em nossa história...

\section{Que projeto orientou o Departamento nos anos 50?}

Já respondi também a esta pergunta. Mas, já que vocês falam tanto em projeto - no sentido sartriano, com certeza - tenho a dizer que, nem o saudoso Lívio Teixeira nem eu, éramos muito projetistas. Nós, sob certo aspecto, éramos um pouco como o Getúlio, que dizia: "Deixa como está para ver como fica". O Departamento ia se diferenciando natural e lentamente, tendo em conta o pessoal docente de que dispunhamos e o heterogêneo pessoal discente que afluía à Faculdade.

\section{Além de possibilitar o surgimento de intelectuais como Antônio Cândido, Sérgio Buarque de Hollanda, de que maneira a Universidade incidiu sobre o processo político, ideológico e cultural do país?}

Em primeiro lugar é preciso dizer que Sérgio Buarque de Hollanda nada deve à Universidade. A Universidade é que lhe deve muito. Sérgio é o fruto da época que antecede à criação da USP. Antônio Cândido, esse sim, talvez seja, em parte, fruto da Universidade. Mas fez muito mais do que lhe deu a
Universidade. Ele e Sérgio, que admiro e estimo, se me afiguram das mais altas inteligências que o país hoje possui.

Por certo, a Universidade alguma coisa fez, com relativo pouco proveito, convenhamos, pelo processo político brasileiro. Paira no entanto uma atmosfera de desconfiança a seu respeito, principalmente em relação às seções de Filosofia e Sociologia.

Culturalmente, já o disse, a Universidade muito fez. Pena que não tenha podido fazer mais...

Como vê hoje os resultados destes 30 anos de trabalho do Departamento de Filosofia? Que resultados gerou e que acha mais importante?

Tenho a impressão que estes 30 anos geraram muita coisa. O fato mesmo de vocês estarem aqui. A Faculdade de Filosofia de Assis é, como outras, o resultado do crescimento da Faculdade de Filosofia de S. Paulo. Aí estiveram Antônio Cândido; o meu saudoso amigo Vítor Ramos, que levaram para o interior um espírito novo.

Mais importante? Mas tudo é importante, desde que se lance a semente da livre crítica. E essas sementes estão lançadas, e germinarão a seu tempo. E mister que a terra lhes dê seiva. Essa é a minha esperança.

\section{Em que medida as condições} institucionais (a Universidade) integraram, limitaram ou neutralizaram o seu trabalho?

De 1934 a 1937, nada houve que limitasse ou neutralizasse o nosso trabalho. Não sei em que medida as condições institucionais permitiram integrar o nosso trabalho acadêmico. De 1937 a 1945 temíamos o famoso DIP que, é evidente, limitava o nosso 
trabalho. Depois houve novo período de inteira liberdade.

\section{A Universidade tal como ela era, tal como funcionava, era o lugar ideal para se trabalhar?}

Era. Devo dizer que vivi muito feliz durante os anos que lá trabalhei, até sofrer uma decepção no entardecer de minha vida profissional, um pouco antes de minha aposentadoria. Isso revelou-me que, afinal, eu não havia compreendido a tal realidade que fôra objeto de meu estudo...

\section{Seus cursos faziam sempre referência} a uma

sucessão de "modas" filosóficas. Quais foram as modas filosóficas principais e de que maneira tiveram um papel formador da inteligência no Brasil?

Vocês ainda lembram do que eu dizia em aula!... A Filosofia no Brasil sempre foi um produto de importação. $\mathrm{Eu}$ procurei mostrar isso em meu livro. $\mathrm{Na}$ Colônia, a escolástica importada de Coimbra; no Império, o ecletismo; a seguir o positivismo e o evolucionismo, que chegaram até a República. Depois, o neo-kantismo, um pouco de bergsonismo, muito ralo; o marxismo, o existencialismo e até Husserl, Hartmann e Heidegger! Ouvi dizer que vão traduzir Heidegger! Será um trabalho de Hércules. Mais recentemente, o estruturalismo. Até a fundação da Faculdade de Filosofia, o filoneismo dominou nossa cultura. Era importante haver lido a obra mais recentemente publicada e, de preferência, no original. Mas não se indagava muito se o leitor assimilava o que lera. Assim, a Filosofia, como muito mais, era privilégio de raríssimas pessoas. Com o advento dos cursos regulares de Filosofia, a situação modificou-se em parte. Começamos então a nos vestir mais simplesmente, mais moderadamente, tendo em conta, por certo, a moda, mas sem os atavios e falsos luxos filoneístas. Fugir à moda não é fácil, mas vestir-se com exagero é ridículo. Foi por isso que terminei o meu livro citando Macunaíma, que se farta de todas as comezaimas, de todas as frutas. Fala de indumentária, mas veste-se pouco. Canta todas as canções e dança todas as músicas. É o

herdeiro latino, mas ignorante de todas as culturas...

\section{Como é que vê hoje seus trabalhos?}

Os meus trabalhos... São muito poucos e hoje já tão velhos quanto eu. O meu propósito, já o disse, era trazer a reflexão filosófica ou crítica - e não as filosofias - para o desenrolar da vida brasileira da qual eu acreditava e ainda às vezes acredito - há de emergir uma cultura que nos seja própria, que caracterize o que somos no todo da cultura humana.

\section{As suas preocupações sempre foram com uma \\ filosofia da cultura e, particularmente, com a filosofia política?}

Sim. E por isso - estranhamente incorri em pecados que nunca julguei estar cometendo. Evidentemente, a filosofia conduz à política. Esta me parece o seu natural desembocadouro.

Essas preocupações com a história brasileira, com a reescrita da nossa tradição cultural, foram inspiradas por alguma opção filosófica?

Sim. A reescrita de nossa tradição cultural vem sendo feita pelos historiadores, desde que Sérgio Buarque de Hollanda escreveu o seu Raízes do Brasil e que Gilberto Freyre escreveu Casa Grande e Senzala. Os moços estão ampliando essa nova escrita, às vezes 
com uma dose um pouco forte de sociologismo, mas, ainda assim, isso é de proveito, aparados os exageros.

\section{Quando preparou a "Contribuição"?}

Creio que a vim preparando desde que me tornei mais consciente dos problemas brasileiros, isto é, desde 1928. Escrevi-a entre 1947 e 1949 e ampliei-a, a pedido da Editôra José Olympio, em 1955.

\section{Qual foi o seu interesse pelo positivismo?}

Como vocês sabem, não sou positivista. Mas atraiu-me o "fenômeno" positivista no Brasil que, por sinal, deve ser ainda melhor estudado. É algo de estranho o aparecimento do positivismo no Brasil. Creio que as razões que dei, e que outros deram, não são suficientes. Espero que alguém estude melhor o caso.

Qual o significado que atribui à ironia em seu trabalho filosófico?

O mesmo que Sócrates atribuía. Ironia e maiêutica, fontes da crítica, são consubstanciais ao trabalho filosófico.

Tem o nacionalismo alguma influência em seu trabalho? De que maneira via a produção isebiana?

Não, o nacionalismo não teve influência em meu trabalho. Quanto à produção isebiana, em parte, ela foi muito proveitosa.

\section{São irreconciliáveis filosofia política e} filosofia das ciências?

Não creio, embora eu confesse nada entender de filosofia das ciências. Por falta, é claro, de uma boa formação científica.
Se pudesse pensar hoje o curso de filosofia, que exigências formularia para ele?

É coisa que não me acode agora, pois há onze anos que estou fora da .... Universidade e não conheço o nível de cultura dos estudantes que procuram a Faculdade. $\mathrm{O}$ que posso dizer é que um curso de filosofia pode ser iniciado de várias maneiras: pela matemática, pelas ciências, pela literatura, pela história. $\mathrm{O}$ essencial é que o estudante tenha gôsto (?) por aquilo que estuda e queira ir mais longe.

Nos movimentos estudantis que culminaram nas paritárias em 68, o Departamento de Filosofia sofreu um sério questionamento por parte dos alunos e de alguns professores; e uma das críticas era a seguinte: os professores pesquisadores em filosofia estariam condescendendo em uma atividade meramente acadêmica de produzir monografias sobre os filósofos, em trabalho que, embora formalmente rigoroso, pouco teria a ver com o genuíno exercício do espírito filosófico, que com isso acabaria se desvitalizando e se tornando incapaz de contribuir para a compreensão dos problemas filosóficos contemporâneos. Como viu essa crítica?

Em primeiro lugar, não creio que o trabalho monográfico, que julgo muito útil, pouco tem a ver com o genuíno (?) espírito filosófico. Afinal, qual o critério para julgar se um trabalho ou outro de filosofia é genuíno? Caráter genuíno (próprio, verdadeiro, natural, exato, legítimo, puro) é dado pelo próprio trabalho e não há regras ou normas para ditá-lo. Ao questionamento referido, a meu ver, faltou espírito filosófico... Nos movimentos estudantis de 68, que se deram em toda parte, houve, como é 
sabido, muita paixão. $\mathrm{E}$ a paixão não se dá bem com a razão...

\section{Como é que o marxismo teria tido influência em suas preocupações?}

Sou homem de meu tempo e sofri a influência da obra de Marx que, como já lhes disse, comecei a conhecer em Paris, ao mesmo tempo que começava a ler Freud. Não entendo, porém, as filosofias como pontos fixos, imutáveis e invariáveis. Elas são marcos de referência na compreensão do homem e da vida, em vários momentos da história. O desfilar de doutrinas no correr da história é algo que ao mesmo tempo encanta e desencanta. $O$ essencial na filosofia, não são as filosofias, mas o espírito que emana do encontro e desencontro das idéias. "Toda a teoria é névoa", já dizia Goethe (tão esquecido hoje). O que conta é a "Ârvore da vida"...

\section{Como caracterizaria a ideologia?}

E perigosa essa palavra e pode ser tomada em vários sentidos. Dela muito se abusou. Afinal, a meu ver, quem melhor a definiu foi Engels, em carta a F. Mehring, de 14 de julho de 1893. Nada tenho a acrescentar ao pensamento de Engels.

Acha que é possível, por exemplo, uma filosofia como crítica? Ela tem que ter duas coisas fundamentalmente: um certo enraizamento numa tradição cultural $e$, ao mesmo tempo, um diálogo quase que internacional com as principais produções?

Por certo: a filosofia é crítica. E enraiza-se na tradição de uma cultura, em diálogo constante com as produções de outras fontes e tradições culturais. $\mathrm{O}$ que nos falta, ou melhor, aquilo a que não temos prestado a devida atenção e cuidado é à nossa tradição cultural, à nossa maneira de ser. Sobra-nos, no entanto, não um diálogo, mas o monólogo das produções internacionais. Não sei se me fiz entender...

Como interpreta hoje a produção, de ordem filosófica, com a linguagem?

Os estudos linguísticos são de grande importância para o esclarecimento dos conceitos filosóficos. Mas eu nada entendo de assuntos linguísticos e, por isso, não ouso falar sobre isso. Apenas noto que, de uns tempos para cá, enquanto a linguagem comum piorava muito, a filosófica - do mesmo modo que a sociológica e econômica ficaram, para nós, do vulgo, um tanto (ou mesmo muito) herméticas. Há um economês, um sociologuês e logo, um filosofoguês. O alcance dessa disciplinas, assim, diminui e isso não me parece proveitoso para a cultura geral.

Hoje Oswald de Andrade é de certa forma recuperado pela tradição cultural. Na sua opinião que importância teve ele? Qual foi o projeto dele?

Eu conheci já tarde, uns dez anos antes de sua morte, o Oswald de Andrade. Tivemos boas relações e só uma vez ele fez piada comigo. Era um homem bom, mas criava inimigos por causa das piadas que inventava. Foi o escândalo no meio intelectual paulista anterior a 1922.

Quando eu era menino, lia muito o Pirralho, que era dele e de outros de sua geração. Não perdia o Juó Bananere que era publicado no Pirralho. Depois perdi o Oswald de Andrade de vista, embora tomasse conhecimento de sua vida tumultuosa. Vim a conhecê-lo já assistente da Faculdade, e ele candidato ao concurso que eu também faria. Estivemos juntos várias vezes e a minha simpatia cresceu pelo meu 
concorrente. Não é aqui o lugar para lembrar muitas das excelentes piadas que ele me contou quando me procurava para esclarecer alguma questão filosófica. Mas uma eu vou contar; realizava-se em S. Paulo um congresso filosófico. O Oswald lá estava. Fui procurar um amigo que também participava do Congresso e nesse momento, dois "filósofos" discutiam muito e inutilmente, um assunto qualquer de ontologia. Levanta-se o Oswald e pede a palavra. Vai ao palco, apanha o microfone e muito seriamente diz: "O problema hoje não é mais de ontologia. É de odontologia.”. . .

Oswald não perdia vez para piada.

Qual a sua importância? Teve importância, mas, melhor do que eu, aí estão os especialistas em literatura para dizê-lo. Projeto do Oswald? Desconfio que não tinha nenhum.

\section{Poderia explicar as razões de sua desconfiança em relação à filosofia da História? \\ Vocês me metem em cada entaladela... É, não confio muito}

nessas vastas sínteses que são as filosofias da História. Prefiro a História. Prefiro a filosofia.

Certa vez procurou-me um estudante de história, que pretendia fazer uma tese sobre a Filosofia da História do Positivismo. Ele, simplesmente, não havia estudado os documentos muitos - relativos ao positivismo. A gente não pode desiludir os moços... Assim, como ele era estudante de história, aconselhei-o que fizesse uma pesquisa na Inspetoria de Imigrantes e nos papéis das Docas, a ver se descobria, num período de 10 ou 15 anos, quantos imigrantes italianos haviam entrado em S. Paulo, suas idades, família, profissões e como se espalharam pelas diversas zonas do Estado, etc.

Olhou-me e disse-me: "mas isso seria uma tese muito banal..." Deu-me as costas e nunca mais o vi. Mas é com teses assim, banais, muitas e muitas, que um dia poderemos talvez nos aproximar de uma filosofia da história. Como dizia Mário de Andrade: "é com muita e muita análise que chegamos a alguma síntese..." 